\title{
Evaluating tourniquet use in Swedish prehospital care for civilian extremity trauma
}

\author{
Eric Wellme ${ }^{1} \cdot$ Victor Mill $^{1} \cdot$ Carl Montán ${ }^{1,2}$
}

Received: 21 October 2019 / Accepted: 2 March 2020 / Published online: 29 April 2020

(c) The Author(s) 2020

\begin{abstract}
Purpose The use of tourniquet (TQ) is today a well-documented and lifesaving adjunct to control bleeding from extremity trauma in the military setting. Since August 2015, the ambulance services in Stockholm, Sweden are equipped with TQs. The implementation and potential complications related to TQ use have so far not been evaluated. The primary aim of this study was to evaluate the prehospital use of TQ for haemorrhage control in extremity trauma. Possible complications following the use of TQ were analysed.

Methods A retrospective, descriptive cohort study of extremity haemorrhage for all patients $(n=56)$ with a documented prehospital use of TQ admitted to the trauma centre at Karolinska University Hospital from 1st August 2015 to 31st December 2017 was conducted. Data regarding TQ use including indication, duration, bleeding volume, complications and definitive injury were analysed.

Results Out of 63 placements of TQ in 56 patients, TQ stopped the bleeding effectively in $98.2 \%$ of the cases and the TQ time varied from 15 to $100 \mathrm{~min}$. The overall complication rate was $30.1 \%$; however, complications possibly related to TQ use were 3.6\%. In 16 (28.6\%) cases, the TQ were used for a non-life-threating haemorrhage which may have been stopped with direct pressure only.

Conclusion This study shows TQs to be an effective but overused tool in haemorrhage control. The use of TQ was not associated with any severe complications, implying the safety and effectiveness of the device in the civilian setting if TQ time is kept under $100 \mathrm{~min}$.
\end{abstract}

Keywords Haemorrhage $\cdot$ Tourniquet $\cdot$ Extremity trauma $\cdot$ Prehospital $\cdot$ Bleeding $\cdot$ Civilian

\section{Introduction}

Trauma is the most common cause of death in Sweden among people in the ages between 15 and 44 [1]. Uncontrolled haemorrhage is, after neurotrauma, the leading cause of death in civilian trauma. A study from 2014 [2], suggested that approximately $28 \%$ of all trauma patients had potentially

Carl Montán

carl.montan@sll.se

Eric Wellme

eric.wellme@stud.ki.se

Victor Mill

victor.a.mill@gmail.com

1 Department of Medicine and Surgery, Karolinska Institutet, Stockholm, Sweden

2 Department of Vascular Surgery, Karolinska University Hospital Solna, 17176 Stockholm, Sweden survivable injuries if given the correct treatment. Out of the possibly preventable deaths, over $50 \%$ were caused by uncontrolled haemorrhage [2]. Rapid control and treatment of significant bleeding in trauma patients is, therefore, vital [3]. In the city region of Stockholm, tourniquets (TQs) (brand name $\mathrm{CAT}^{\circledR}$ ) were introduced as a tool for prehospital ambulances in August 2015.

The majority of literature supporting the use of TQs is based on data from military conflicts where the use of TQs is associated with improved survival and a low complication rate in severe extremity trauma [4]. The use of TQ in civilian trauma has only recently been adopted, due to concerns of complications such as nerve damage, compartment syndrome, amputation, secondary vascular and tissue injuries $[5,6]$.

In Sweden, no official guidelines have been published for the civilian ambulance services regarding indications for TQ in trauma [7]. The primary aim of this study was to 
evaluate the prehospital use of TQ for haemorrhage control in extremity trauma and to analyse possible complications of TQ use and the conjunctive measures such as blood transfusion.

\section{Methods and materials}

This was a retrospective, descriptive cohort study of all adult (>16 years) extremity trauma patients with bleeding and documented use of TQ admitted to Karolinska University Hospital Stockholm, Sweden between 1st of August 2015 and 31st of December 2017. Patients were identified using ICD coding, corresponding to injuries where TQ might have been indicated. Indication for application of TQ was evaluated with regard to the final diagnosis (given in hospital) to assess if an overuse of TQ could be suspected in comparison to only using covering pressure bandage.

Patients' data (including TQ time, physical parameters and laboratory data) were extracted from computerized prehospital and hospital medical records. In cases where data were missing, the prehospital medical records systems were used and vice versa. Patients were cross-checked with the local transfusion registry. Injury severity score (ISS) was retrieved from the local trauma registry at Karolinska University hospital.

Mortality and complications possibly related to TQ use (i.e. compartment syndrome, amputation, secondary nerve injuries and kidney injury) were analysed.

Results and outcome measures were analysed using IBM $^{\circledR}$ SPSS Statistics ${ }^{\circledR}$ for Macintosh version 24.0 (Armonk, New York, USA).

Ethical permission for this study was given from the local Ethical Review Board in Stockholm, Sweden (Reference number 2018/200-31).

\section{Results}

During the study period, 662 patients with extremity trauma were admitted to the trauma unit. Out of these, 303 patients' admission notes and ambulance reports were analysed. Fiftysix patients with a documented prehospital placement of TQ were identified and included in the study (50 males and 6 females) (Table 1). Paediatric patients, burn trauma and military trauma were excluded. Flowchart for patient identification described in Fig. 1. 12 patients needed intensive care with a mean length of stay in the intensive care unit (ICU) of 7.58 days. Out of the 36 patients arriving with ambulance, 31 patients had a Glasgow Coma Scale (GCS) between 14 and 15 prior arriving to hospital, indicating that the majority of the patients were awake with minor risk of brain damage. The most frequent mechanism of injury was
Table 1 Demographic and clinical parameters of patients with a placement of tourniquets

\begin{tabular}{lll}
\hline Demographics & & $N$ (range) \\
\hline Age, median & & $31(17-80)$ \\
Gender, men $(\%)$ & $50(89.3 \%)$ \\
Length of Stay, median & & $3(1-62)$ \\
Days in ICU, median & & $0(0-26)$ \\
Prehospital vital signs & Median (IQR) & Range \\
Pulse, beats/min $(n=38)$ & $85(70 ; 115)$ & $(0-142)$ \\
Systolic blood pressure, mmHg & $115(100 ; 140)$ & $(0-170)$ \\
$\quad(n=33)$ & & \\
Vital signs on admission & Median (IQR) & Range \\
Pulse, beats/min $(n=47)$ & $90(75 ; 100)$ & $(0-150)$ \\
Systolic blood pressure, mmHg & $122(110 ; 140)$ & $(0-180)$ \\
$\quad(n=48)$ & & \\
ISS, $(n=54)$ & $9(4 ; 16.25)$ & $(1-75)$ \\
Blood transfusion, yes $(\%)$ & $18(32.1 \%)$ & \\
Massive blood transfusion, yes $(\%)$ & $8(14.3 \%)$ & \\
Labs on admission & Median (IQR) & Range \\
Haemoglobin, mg/l $(n=55)$ & $138(118 ; 146)$ & $(82-168)$ \\
PK(INR) $(n=50)$ & $1.1(1.0 ; 1.1)$ & $(0.9-2.7)$ \\
Fibrinogen, g/l $(n=49)$ & $2.3(1.8 ; 3.0)$ & $(0.9-4.3)$ \\
Creatinine, micromole/l $(n=54)$ & $90.5(74.5 ; 101)$ & $(51-131)$ \\
pH $(n=40)$ & $7.36(7.31 ; 7.39)$ & $(6.8-7.56)$ \\
Lactate, mg/dl $(n=41)$ & $2.6(1.7 ; 4.8)$ & $(0.7-13.7)$ \\
\hline
\end{tabular}

Contains information regarding $n=56$ patients. Where indicated, not all patients were included

$I C U$ intensive care unit, ISS Injury Severity Score, $I Q R$ interquartile range $25 ; 75$ percentiles

penetrating trauma caused by knives or firearms (Fig. 2). Among blunt trauma, the majority of injuries were caused by traffic accidents (Table 2; Fig. 2).

The foremost indication ( $>50 \%$ ) for a placement of TQ was potentially life-threatening haemorrhage (Table 3). In several cases, a pulsating bleeding was present. Documented TQ time ranged from 15 to $100 \mathrm{~min}$ in 21 patients, in more than $50 \%$ of the cases data on TQ time was missing.

Based on medical records from the ambulance and the admission note, 16 (28.6\%) of the injuries were categorised as non-life threatening. In four of these cases, the TQ was removed completely upon arrival at the scene by ambulance personnel, in all cases because of an unindicated use with no active bleeding.

In all but one patient, the TQ was sufficient to stop the bleeding effectively without the addition of a pressure bandage, making the TQ effective in $98.2 \%$ of the cases. No patient received two TQs on the same limb. In patients with a potentially life-threating haemorrhage, the TQ was applied after an attempt to stop the bleeding with direct pressure in more than $40 \%$ of the cases. 
Fig. 1 Flowchart describing how patients were identified for inclusion in study according to whether they received tourniquet or not. ICD-10 = International Statistical Classification of Diseases and Related Health Problems, 10th revision

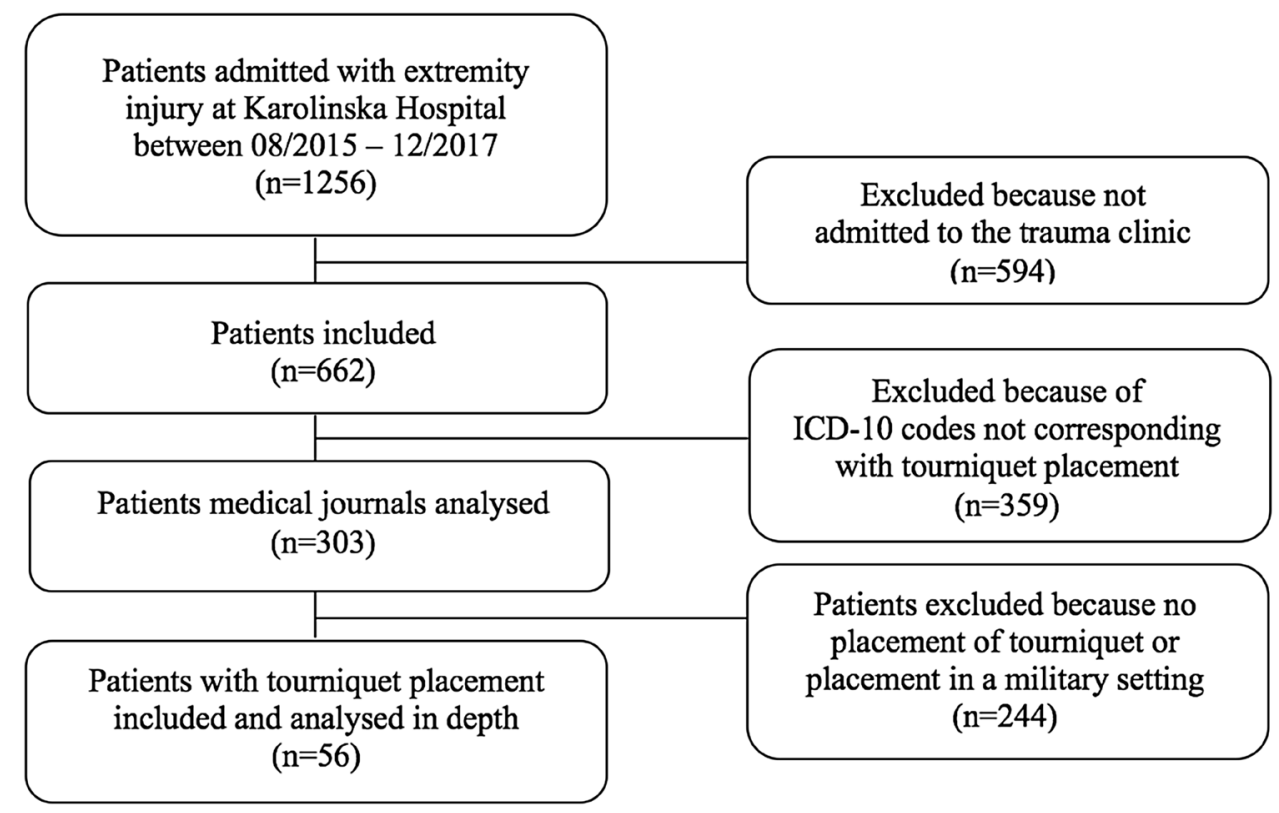

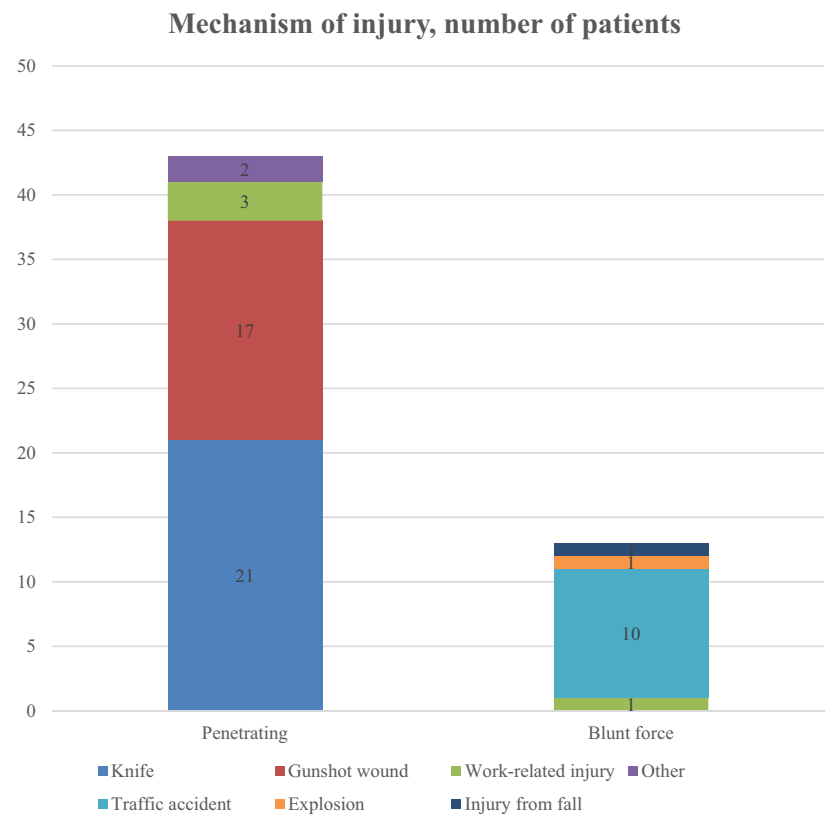

Fig. 2 Mechanism of injury indicating use of tourniquet. 63 tourniquets in 56 patients

Almost one third (32.1\%) of the patients had injuries requiring blood transfusion (Table 4). Eight of these received blood according to a massive transfusion protocol. In this group, four patients had a fibrinogen equal to or lower than $1.7 \mathrm{~g} / \mathrm{l}$; however, no correlation was found between low fibrinogen and blood transfusion. In one case, a blood pressure cuff was used as TQ and in nine cases, an improvised TQ was placed; most frequently a belt but also bed sheets and in one case, a dog leash. In four of these
Table 3 The use of tourniquet

\begin{tabular}{ll}
\hline & $N(\%)$ \\
\hline Indications & \\
Potentially life-threatening haemorrhage & $27(48.6)$ \\
Traumatic amputation & $5(8.9)$ \\
Open fracture & $8(14.3)$ \\
Non-life-threatening haemorrhage & $16(28.6)$ \\
TQ location & \\
Upper limb & $10(17.9)$ \\
Lower limb & $46(82.1)$ \\
TQ time, minutes ( $n=21)$ median (IQR) & $60(30 ; 60)$ \\
Patients with more than one TQ & $7(12.5)$ \\
Attempt with direct pressure before placement of TQ & \\
Yes & $19(33.9)$ \\
No & $12(21.4)$ \\
Unknown & $25(44.6)$ \\
Who placed the TQ & \\
Ambulance & $27(48.2)$ \\
Police & $18(32.1)$ \\
Emergency services & $1(1.8)$ \\
Bystanders & $6(11.5)$ \\
Unknown & $4(7.1)$ \\
\hline
\end{tabular}

Contains information regarding $(n=56)$ patients. Where indicated, not all patients were included

$T Q$ tourniquet. $I Q R$ interquartile range $25 ; 75$ percentiles

cases, the improvised TQ was replaced by a commercial TQ upon arrival of prehospital personnel.

Death occurred in two cases (30-day mortality 3.6\%). Both patients arrived at the trauma unit with ongoing CPR. The first patient died in the ICU due to anoxic brain injury 
Table 4 Specification of blood products for patients $(n=18)$ who received blood transfusion

Table 2 Mechanism of injury indicating use of tourniquet

\begin{tabular}{ll}
\hline Blood product & $\begin{array}{l}\text { Number of } \\
\text { units. mean } \\
\text { (range) }\end{array}$ \\
\hline Erythrocytes & $11(2-45)$ \\
Plasma & $5.67(0-22)$ \\
Platelets & $1.22(0-8)$ \\
\hline
\end{tabular}

\begin{tabular}{ll}
\hline Mechanism of injury & $N(\%)$ \\
\hline Penetrating & $43(76.8)$ \\
Knife & $21(37.5)$ \\
Gunshot wound & $17(30.4)$ \\
Work-related injury & $3(5.4)$ \\
Other & $2(3.6)$ \\
Blunt force & $13(23.2)$ \\
Traffic accident & $10(17.9)$ \\
Explosion & $1(1.8)$ \\
Work-related injury & $1(1.8)$ \\
Injury from fall & $1(1.8)$ \\
\hline
\end{tabular}

63 tourniquets in 56 patients

2 days after admission following complications to massive haemorrhage from a stab wound in the femoral artery. The second patient was declared dead upon arrival to the trauma unit after multiple gunshot wounds to the chest and arms. The leading cause of death in both cases were exsanguination.

The total rate of complications was $30.1 \%$ (Table 5). There were seven amputations, five of which were traumatic due to the initial trauma. Two below knee amputations were necessary after admission to hospital, one due to post-operative infection and one following the initial trauma with development of necrotic ulcers. No amputations due to TQ use were seen in this study.

Four patients acquired a fasciotomy, of these three were made prophylactic. One case of compartment syndrome was identified. Three patients developed secondary acute kidney injury (AKI), one case due to fluid overload and pulmonary oedema, one due to septic shock and multi-organ failure, 7 days post-trauma and one due to hypoperfusion and rhabdomyolysis due to compartment syndrome. The latter two cases needed haemodialysis over a period.

Nerve damage was seen in 13 (23.2\%) of the patients. In eight of these cases, the damage was clearly described to be caused by the initial trauma. In two cases, the nerve injury might have been caused by the application of TQ, according to the information provided in the medical records. In these cases, the nerve function recovered within 2 weeks. In three patients, it was not possible to verify the cause of the nerve damage; however, in these cases, the damage to the nerve

Table 5 Mortality and complications

\begin{tabular}{ll}
\hline & $N(\%)$ \\
\hline 30-day mortality & $2(3.6)$ \\
Total complications $^{\mathrm{a}}$ & $17(30.1)$ \\
Amputations following admission to hospital $_{\text {Fasciotomy }}$ & 2 \\
$\quad$ Prophylactic & 4 \\
Compartment syndrome & 3 \\
Acute kidney injury & 1 \\
Nerve damage & 3 \\
$\quad$ Loss of motor function & 13 \\
$\quad$ Loss of sensory function & 10 \\
Other & 11 \\
No complications & 1 \\
\hline
\end{tabular}

Total frequency of mortality and complications related to either direct trauma or the use of tourniquet

${ }^{a}$ Four patients suffered more than one complication

${ }^{b}$ Eight patients had both loss of motor and sensory function

was more distally than the site of the TQ. The nerve damage for 12 of the patients were transient within 2 weeks of the trauma. One patient with sensory nerve damage, due to the initial trauma, required 8 months until full recovery.

One patient developed a subcutaneous hematoma at the site of the TQ.

All patients were categorized into three groups depending on the final diagnosis after admission-vascular damage, deep tissue damage and superficial tissue damage (Table 6; Fig. 3). All 14 (25\%) patients in the first category needed vascular surgery or intervention. Patients in the second category $(n=25,44.6 \%)$ required orthopaedic surgery, and wound revision. The 17 (30.4\%) patients with a superficial tissue damage needed skin sutures, wound dressing or no intervention at all. The majority of patients in this group had an injury categorized as non-life threatening.

\section{Discussion}

This study provides the first evaluation of TQ use in Sweden since the formal introduction of the device in 2015 . The results demonstrate an overuse based on the actual

Table 6 Patients categorized according to type of damage

\begin{tabular}{ll}
\hline & $N(\%)$ \\
\hline Vascular damage & $14(25.0)$ \\
Deeper tissue damage & $25(44.6)$ \\
Superficial tissue damage & $17(30.4)$
\end{tabular}

Damages according to ICD-10 codes and intervention done after admission to hospital 


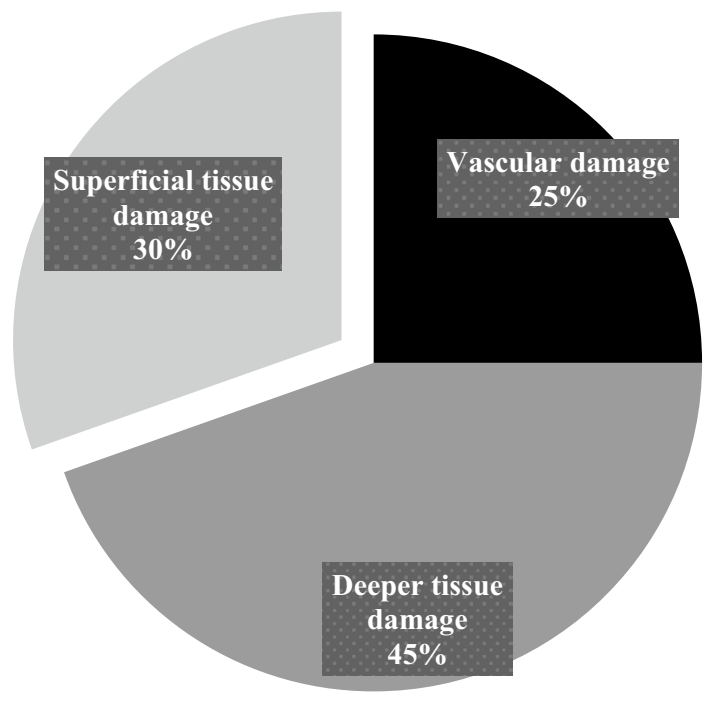

Fig. 3 Patients categorized according to type of damage. Damages according to ICD-10 codes and intervention done after admission to hospital

injury from the discharge note and the interventions performed at the trauma unit. Complications due to the use of TQ were low, two patients (3.6\%) suffered transient nerve damage, it could not be determined if the cause was due to the use of a TQ, the initial trauma or a combination of both. Our results are consistent with three other studies from a military environment [8-10]. In a study by Lakstein et al. [10], five patients (5.5\%) out of 91 suffered nerve damage attributed to the use of TQ, all affected patients had a TQ time over $100 \mathrm{~min}$. Kragh et al. [8] reported a $1.7 \%$ complication rate in form of transient nerve damage at the site of TQ. Experiences from the United Kingdom military shows similar data where three complications were seen following over 100 TQ applications [9]. Most studies to date are based on military populations from conflict zones. However, recent studies have been conducted in a civilian environment $[5,11]$ with similar results. In contrast to previous fears, data indicate a low complications rate-at least with a TQ time below $100 \mathrm{~min}$.

In the year of 1916, TQ was described as "...the invention of the evil one" [12] and in a study from 1962, it is stated that there is no place for TQ as an adjunct in acute bleeding [13]. As more recent studies have shown, the TQ is an effective and safe device in the initial care of the trauma patient, in both military [10] and civilian settings [14].

Our data indicate an overuse of TQ, as 30\% of the applications were to non-life-threatening superficial tissue injuries. Bleeding from these injuries may have stopped by direct pressure only. This is a known phenomenon when handling an external bleeding, especially after gun violence [15]. In at least $20 \%$ of the cases, direct pressure was not tried prior to application of TQ. This indicates the need of an algorithm or guidelines for the use of TQ; guiding medical personnel in the field to a safe use and to minimize unindicated applications of the device.

However, none of the patients with superficial damages acquired any complication that could be related to TQ use, demonstrating that TQs can be used safely also for minor injuries. Some studies even promote an expanded use of TQ for the civilian trauma patient, stating that the risk of complications is low and that TQs are safe to use [4, 16, 17]. Cornelius et al. [18] seconds the claim and recommends the use of TQ, to minimize TQ time they advocate short transportation time to hospital.

None of the patients had a measured TQ time longer than $100 \mathrm{~min}$. The reasons why no TQ time exceeded $2 \mathrm{~h}$ may be due to short transport times within Stockholm and early transport from the trauma scene. This is also seen in other studies conducted in a civilian environment [4].

In over $30 \%$ of the cases, police officers applied the TQ, mainly because they were the first responder on scene. No significant difference in complication rates was seen between TQs applied by police or ambulance personnel, a statement also observed in another study [19]. This demonstrates the benefit of all first responders, regardless of profession, being equipped with a TQ for a quick and easy tool in the initial care of a patient with extremity haemorrhage.

This study carries many limitations due to its retrospective nature. There are several cases of missing data, probably because the accumulated data have been collected from four different systems for registration (two registries and two computerized medical record systems).

A structured feedback and follow-up after introducing new devices and techniques to the Stockholm ambulance services seems to be lacking. This is the first evaluation of TQ since the implementation in 2015. To this date, no official guidelines for TQ use have been published for the ambulance services.

In conclusion, this study has proven TQs to be an effective but overused device, since the implementation of tourniquets for our ambulance services in 2015. The use of TQ was not associated with any severe complications implying both the benefit and safety of the device-if the TQ time is kept under $100 \mathrm{~min}$. To minimize overuse, official guidelines for managing extremity bleeding could be helpful and improve safety for the civilian trauma patient.

Acknowledgements Open access funding provided by Karolinska Institute. Secretary Sandra Lang contributed with the identification of patients from medical records, Agneta Wikman, MD, PhD made the cross reference with the Transfusion registry and Veronica Vicente, reg nurse, $\mathrm{PhD}$ contributed with prehospital data used in Table 1 and also information where prehospital medical records were missing from the Hospital medical records. 


\section{Compliance with ethical standards}

Conflict of interest The authors declare that they have no conflicts of interest.

Open Access This article is licensed under a Creative Commons Attribution 4.0 International License, which permits use, sharing, adaptation, distribution and reproduction in any medium or format, as long as you give appropriate credit to the original author(s) and the source, provide a link to the Creative Commons licence, and indicate if changes were made. The images or other third party material in this article are included in the article's Creative Commons licence, unless indicated otherwise in a credit line to the material. If material is not included in the article's Creative Commons licence and your intended use is not permitted by statutory regulation or exceeds the permitted use, you will need to obtain permission directly from the copyright holder. To view a copy of this licence, visit http://creativecommons.org/licenses/by/4.0/.

\section{References}

1. Socialstyrelsen. Statistik om dödsorsaker 2016. Stockholm: Socialstyrelsen; 2017.

2. Davis JS, Satahoo SS, Butler FK, Dermer H, Naranjo D, Julien $\mathrm{K}$, et al. An analysis of prehospital deaths: Who can we save? J Trauma Acute Care Surg. 2014;77(2):213-8. https://doi. org/10.1097/TA.0000000000000292.

3. Dorlac WC, DeBakey ME, Holcomb JB, Fagan SP, Kwong KL, Dorlac GR, et al. Mortality from isolated civilian penetrating extremity injury. J Trauma. 2005;59(1):217-22.

4. Inaba K, Siboni S, Resnick S, Zhu J, Wong MD, Haltmeier T, et al. Tourniquet use for civilian extremity trauma. J Trauma Acute Care Surg. 2015;79(2):232-7. https://doi.org/10.1097/TA.0000000000 000747(Quiz 332-3).

5. Scerbo MH, Mumm JP, Gates K, Love JD, Wade CE, Holcomb $\mathrm{JB}$, et al. Safety and appropriateness of tourniquets in 105 civilians. Prehosp Emerg Care. 2016;20(6):712-22. https://doi. org/10.1080/10903127.2016.1182606.

6. Singletary EM, Charlton NP, Epstein JL, Ferguson JD, Jensen JL, MacPherson AI, et al. Part 15: First Aid. 2015 American Heart Association and American red Cross Guidelines. Update First Aid. 2015;132(182 suppl 2):S574-S589589. https://doi. org/10.1161/cir.0000000000000269.

7. Medicinska riktlinjer för ambulanssjukvården. Stockholm 2017. https://www.s112.se/wp-content/uploads/2017/09/ AB-2017_medicinska_behandlingsriktlinjer.pdf
8. Kragh JF, Walters TJ, Baer DG, Fox CJ, Wade CE, Salinas J, et al. Survival with emergency tourniquet use to stop bleeding in major limb trauma. Ann Surg. 2009;249(1):1-7. https://doi.org/10.1097/ SLA.0b013e31818842ba.

9. Brodie S, Hodgetts TJ, Ollerton J, McLeod J, Lambert P, Mahoney P. Tourniquet use in combat trauma: UK military experience. J R Army Med Corps. 2007;153(4):310-3.

10. Lakstein D, Blumenfeld A, Sokolov T, Lin G, Bssorai R, Lynn $\mathrm{M}$, et al. Tourniquets for hemorrhage control on the battlefield: a 4-year accumulated experience. J Trauma. 2003;54(5 Suppl):S221-S22525. https://doi.org/10.1097/01.TA.0000047227 33395.49

11. Kue RC, Temin ES, Weiner SG, Gates J, Coleman MH, Fisher J, et al. Tourniquet use in a civilian emergency medical services setting: a descriptive analysis of the boston EMS experience. Prehosp Emerg Care. 2015;19(3):399-404. https://doi.org/10.3109/10903 127.2014.995842.

12. Blackwood M, Royal Army Medical Corps, 3rd Corps Medical Society. Treatment of wounds from fire trench to field ambulance. J R Army Med Corps. 2001;147(2):230-5 (Discussion 29).

13. Klenerman L. The tourniquet in surgery. J Bone Jt Surg Br. 1962;44-B:937-43.

14. Beaucreux C, Vivien B, Miles E, Ausset S, Pasquier P. Application of tourniquet in civilian trauma: systematic review of the literature. Anaesth Crit Care Pain Med. 2018. https://doi.org/10.1016/j. accpm.2017.11.017 (Forthcoming planned).

15. Lee C, Porter KM, Hodgetts TJ. Tourniquet use in the civilian prehospital setting. Emerg Med J. 2007;24(8):584-7. https://doi. org/10.1136/emj.2007.046359.

16. Doyle GS, Taillac PP. Tourniquets: a review of current use with proposals for expanded prehospital use. Prehosp Emerg Care. 2008;12(2):241-56. https://doi.org/10.1080/10903120801907570.

17. Ode G, Studnek J, Seymour R, Bosse MJ, Hsu JR. Emergency tourniquets for civilians: can military lessons in extremity hemorrhage be translated? J Trauma Acute Care Surg. 2015;79(4):58691. https://doi.org/10.1097/TA.0000000000000815.

18. Cornelius B, Campbell R, McGauly P. Tourniquets in trauma care: a review of application. J Trauma Nurs. 2017;24(3):203-7. https ://doi.org/10.1097/JTN.0000000000000290.

19. Callaway DW, Robertson J, Sztajnkrycer MD. Law enforcement-applied tourniquets: a case series of life-saving interventions. Prehosp Emerg Care. 2015;19(2):320-7. https://doi. org/10.3109/10903127.2014.964893. 